\title{
FORMULATION AND EVALUATION OF LORNOXICAM MICROSPONGES USING EUDRAGIT RS 100 AND EUDRAGIT RSPO
}

\author{
BANNARAVURI THIREESHA, AYYA RAJENDRA PRASAD*, HAROLED PETER P L \\ Department of Pharmaceutics, Nirmala College of Pharmacy, Mangalagiri - 522 503, Andhra Pradesh, India. \\ Email: dr.ayyarajendraprasad@gmail.com
}

Received: 24 June 2018, Revised and Accepted: 14 June 2018

\section{ABSTRACT}

Objective: The objective of the present study was preparation and evaluation of lornoxicam microsponges to prolong their drug release up to $12 \mathrm{~h}$ for effective osteoarthritis, rheumatoid arthritis, and acute lumbar-sciatica therapy.

Methods: Lornoxicam microsponges were prepared by the quasi-emulsion solvent diffusion technique using different concentrations of polymers such as Eudragit RS 100 and Eudragit RSPO in ethanol and dichloromethane organic solvent mixture. Microsponges were evaluated for their particle size, percentage yield, entrapment efficiency, scanning electron microscopy (SEM), and in vitro drug release studies.

Results: The percentage yield, entrapment efficiency, average particle size, and in vitro drug release for optimized formulation F12 were found to be $70.23 \% \mathrm{w} / \mathrm{w}, 81.34 \% \mathrm{w} / \mathrm{w}, 172.72 \mu \mathrm{m}$, and $96.64 \%$ up to $8 \mathrm{~h}$, respectively. From SEM, it was observed that microsponges were found to be spherical in shape with rough surface texture. The formulation F12 shows zero-order release kinetics with an $\mathrm{r}^{2}$ value of 0.961 and the value of Korsmeyer-Peppas model was found to be 0.792 ; it follows super case II non-Fickian diffusion. The in vitro drug release studies showed that formulations comprised varying concentrations of Eudragit RSPO in higher proportion exhibited much-retarded drug release as compared to formulations comprised a higher proportion of varying concentrations of Eudragit RS 100.

Conclusion: Among all the formulations F12 shows better results, which are released more than $80 \%$ of the drug release within 8 h; hence, it is optimized. These developed microsponges are releasing the drug for a longer period, which will be effective for osteoarthritis, rheumatoid arthritis, and acute lumbar sciatica therapy.

Keywords: Lornoxicam, Microsponges, Quasi-emulsion solvent diffusion method, Eudragit RS 100, Eudragit RSPO.

(C) 2018 The Authors. Published by Innovare Academic Sciences Pvt Ltd. This is an open access article under the CC BY license (http://creativecommons. org/licenses/by/4. 0/) DOI: http://dx.doi.org/10.22159/ajpcr.2018.v11i10.26861

\section{INTRODUCTION}

Microsponge delivery system is porous, polymeric microspheres that can entrap broad range of active ingredients and release the drug over an extended period of time [1]. The microsponge technology was developed by won in 1987 [2]. Microsponges are porous microspheres, biologically inert particles that are made of synthetic polymers and the particles serve to protect the entrapped drug compound from physical and environmental degradation [3]. They are tiny sponge-like spherical particles that consist of innumerable of interconnecting voids within a non-collapsible structure with a large porous surface. The size of the microsponges usually ranges from 5 to $300 \mu \mathrm{m}$ in diameter, and a typical $25 \mu \mathrm{m}$ sphere can have as many as 2,50,000 pores and an internal pore structure equivalent to $10 \mathrm{ft}$ in length, providing a total pore volume of about $1 \mathrm{ml} / \mathrm{g}$ [4]. They are used as a carrier system since they have the capacity to entrap a wide range of actives in their non-collapsible structures with porous surface, through which active ingredients are released in a controlled manner. These microsponges entrapped with the drug can be incorporated into formulations such as tablets, capsules, creams, gel, lotions, and powders [5]. This technology also offers entrapment of active pharmaceutical ingredients, increased elegance, improved stability enhanced formulation flexibility, and reduced side effects [6].

Lornoxicam is a nonsteroidal anti-inflammatory drug of the oxicam class with analgesic, anti-inflammatory, and antipyretic properties. Lornoxicam formulations are available in oral and parenteral formulations. Lornoxicam is a yellow or slightly yellowish powder.
It is slightly soluble in water, soluble in methanol and ethanol. Its release from the sustain release dosage form is limited to the lower gastrointestinal tract which consequently leads to a delayed onset of its analgesic action. It is prescribed for osteoarthritis, rheumatoid arthritis, acute lumbar sciatica conditions, and for post-operative pain management. Lornoxicam is given in doses of 8-16 mg daily by mouth for the treatment of pain. Doses above $8 \mathrm{mg}$ should be given in divided doses. Similar doses may be given by intravenous or intramuscular injection, although in rare cases the maximum initial daily dose may be increased to $24 \mathrm{mg}$, treatment by injection should be limited to 2 days [7-9]. The aim of this study was to prepare sustained release lornoxicam microsponge based capsules using polymer such as Eudragit RS 100 and Eudragit RSPO with reduced frequency and side effects, for effective osteoarthritis, rheumatoid arthritis, and acute lumbar sciatica therapy. A comparative study of all the formulations prepared by quasi-emulsion solvent diffusion method was aimed, and the effects of drug-polymer ratios and external phase compositions used on release kinetics have also been studied (Fig. 1).

\section{MATERIALS AND METHODS}

\section{Materials}

Lornoxicam was procured from Pradeep Kumar Pharma Pvt., Ltd. (Mumbai - India), Eudragit RS 100 and Eudragit RSPO are gifted by Evonik Pharma, Mumbai, India. Methanol, ethanol, polyvinyl alcohol (PVA), polyethylene glycol 400, propylene glycol, and potassium dihydrogen orthophosphate were purchased from LOBA Chemie Pvt., Ltd., Mumbai, India. 


\section{Methods}

Procedure for drug and excipients compatibility by Fouriertransform infrared (FTIR) studies

The FTIR spectra of samples of lornoxicam, Eudragit RS 100, Eudragit RSPO, physical mixture of drug and Eudragit RS 100, drug and Eudragit RSPO and drug, Eudragit RS 100 and Eudragit RSPO were recorded by using FTIR spectrometer. Spectra between 4000 and $400 \mathrm{~cm}^{-1}$ of the drug, a before mentioned polymers and for drug-polymers powder mixtures were recorded using FTIR spectrophotometer (Bruker, ATR, version1.2.4) using $\mathrm{KBr}$ pellet technique. In this ATR sampling technique, solid samples to be analyzed should free from moisture. Samples were dried by placing in the oven for $20 \mathrm{~min}$ at $40^{\circ} \mathrm{C}$. One spatula of dried sample placed into mortar and pestle and properly grained. The prepared sample was placed on the crystal of ATR for recording spectrum [10].

\section{Formulation of lornoxicam microsponges}

All the formulations were prepared by the quasi-emulsion solvent diffusion technique using the polymers Eudragit RS 100 and Eudragit RSPO and plasticizers polyethylene glycol 400 and propylene glycol. Drug, polymer, and plasticizer were dissolved in a mixture of ethanol and dichloromethane and then sonicated for $10 \mathrm{~min}$. This solution was poured drop by drop with a syringe into $1000 \mathrm{ml}$ beaker containing $0.75 \% \mathrm{w} / \mathrm{v}$ PVA solution, maintained at a temperature of $30-40^{\circ} \mathrm{C}$ with stirring at 1000-1200 rpm speed for $5 \mathrm{~h}$ to allow the volatile solvent for evaporation. The formulated microsponges were filtered, washed with distilled water and dried at $40^{\circ} \mathrm{C}[5,6,11]$. The various formulations prepared using different polymers and plasticizers with different ratios are shown in Table 1.

\section{Evaluation of lornoxicam microsponges}

\section{Scanning electron microscopy (SEM) studies}

The lornoxicam microsponges were observed under a SEM. The instrument used in this study was Hitachi S-3700N, Japan. The microsponges were mounted directly on the SEM sample stub, using double-sided sticking tape and coated with a gold film (thickness 180$200 \mathrm{~nm}$ ) under reduced pressure.

\section{Particle size analysis}

The particle size was measured using an optical microscope, and the mean particle size was calculated by measuring 100 particles with the help of a calibrated ocular micrometer. The slide containing microsponges were mounted on the stage of the microscope and diameter of at least 100 particles was measured using a calibrated optical micrometer.

\section{Percentage production yield}

The production yield of the microsponges was determined by calculating accurately the initial weight of raw materials and the last weight of microsponges obtained, and their percentage yield $(\mathrm{w} / \mathrm{w})$ was determined using below equation [12].
Yield $(\%)=\frac{\text { Actual weight of the product }}{\text { Total weight of excipient and drug }} \times 100$

\section{Percentage of unentrapped drug}

Formulated microsponges were filtered from PVA solution. Filtered microsponges were washed thoroughly with $0.75 \% \mathrm{w} / \mathrm{v}$ PVA solution, and washings were added to the above filtrate. $5 \mathrm{ml}$ was taken from this mixture of filtrate and washings, and centrifuged for $10 \mathrm{~min}$ and filtered. Filtered sample was suitably diluted with $0.75 \% \mathrm{w} / \mathrm{v}$ PVA solution and analyzed spectrophotometrically at $354 \mathrm{~nm}$ using ultraviolet (UV)-Vis spectrophotometer. Percentage of the unentrapped drug was calculated [13].

Percentage of unentrapped $\operatorname{drug}(\%)$

Amount of drug present

$$
\begin{aligned}
& =\frac{\text { in filtrate }}{\text { Total amount of drug used }} \\
& \text { for microsponges }
\end{aligned}
$$

\section{Entrapment efficiency}

Microsponges equivalent to $16 \mathrm{mg}$ of pure drug was crushed, powdered and was taken in $100 \mathrm{ml}$ volumetric flask. To this, $80 \mathrm{ml}$ of methanol was added and shaken for $1 \mathrm{~h}$ on a mechanical shaker and then sonicated for 5 min to complete removal of lornoxicam from microspheres. After sonication, volume was made up to the mark with methanol. This solution was centrifuged and filtered. Filtered sample was suitably diluted with methanol and analyzed spectrophotometrically at $353 \mathrm{~nm}$ using UV-VIS spectrophotometer. Entrapment efficiency was calculated as follows $[14,15]$.

Entrapment efficiency $(\%)=\frac{\begin{array}{l}\text { Amount of drug present } \\ \text { in filtrate }\end{array}}{\begin{array}{l}\text { Total amount of drug used } \\ \text { for microsponges }\end{array}} \times 100$

\section{In vitro drug release studies \\ Procedure}

In vitro, drug release studies were carried out using USP type II apparatus at $100 \mathrm{rpm}$. Microsponges equivalent to $16 \mathrm{mg}$ of pure drug was added to $900 \mathrm{ml}$ of pH6.8 phosphate buffer which is used as the dissolution medium. The temperature of the dissolution medium was maintained at $37 \pm 0.5^{\circ} \mathrm{C}$. An aliquot ( $5 \mathrm{ml}$ ) of dissolution medium was withdrawn at specific time intervals up to $12 \mathrm{~h}$, filtered and suitably diluted before spectrophotometric analysis. Sink conditions were maintained by replenishing the medium with an equal amount $(5 \mathrm{ml})$ of pH6.8 phosphate buffer. The absorbance of the sample was measured at $357 \mathrm{~nm}$ by UV-Visible spectrophotometer [16]. The concentration of lornoxicam in test samples was calculated using calibration curve. Six samples were run for each formulation in $\mathrm{pH} 6.8$

\begin{tabular}{|c|c|c|c|c|c|c|c|c|c|c|c|c|}
\hline Ingredients & F1 & F2 & F3 & F4 & F5 & F6 & F7 & F8 & F9 & F10 & F11 & F12 \\
\hline Drug: polymer ratio & $1: 1$ & $1: 0.75$ & $1: 0.5$ & $1: 0.5$ & $1: 0.5$ & $1: 0.5$ & $1: 1$ & $1: 0.75$ & $1: 0.5$ & $1: 0.5$ & $1: 0.5$ & $1: 0.5$ \\
\hline Lornoxicam (mg) & 500 & 500 & 500 & 500 & 500 & 500 & 500 & 500 & 500 & 500 & 500 & 500 \\
\hline Eudragit RS 100 (mg) & - & - & - & - & - & - & 500 & 325 & 250 & 250 & 250 & 250 \\
\hline Eudragit RSPO (mg) & 500 & 325 & 250 & 250 & 250 & 250 & - & - & - & - & - & - \\
\hline PEG plasticizer $(\mathrm{ml})$ & 0.5 & 0.5 & - & 0.25 & - & 0.5 & 0.5 & 0.5 & - & 0.25 & - & 0.5 \\
\hline PG plasticizer $(\mathrm{ml})$ & - & - & 0.25 & 0.25 & 0.5 & - & - & - & 0.25 & - & 0.5 & - \\
\hline $0.75 \% \mathrm{w} / \mathrm{v}$ PVA solution $(\mathrm{ml})$ & 500 & 500 & 500 & 500 & 500 & 500 & 500 & 500 & 500 & 500 & 500 & 500 \\
\hline Dichloromethane (ml) & 10 & 10 & 10 & 10 & 10 & 10 & 10 & 10 & 10 & 10 & 10 & 10 \\
\hline
\end{tabular}
phosphate buffer.

Table 1: Formula of lornoxicam microsponges 


\section{RESULTS AND DISCUSSION}

\section{Drug and excipient compatibility studies by FTIR}

FTIR spectrum of lornoxicam was recorded, and spectral interpretation was done. The characteristics IR absorption peaks of lornoxicam $\mathrm{C}=01$ amide stretching at $1641.30 \mathrm{~cm}^{-1}, \mathrm{~N}-\mathrm{H} 2^{\circ}$ amide stretching at $3122.62 \mathrm{~cm}^{-1}, \mathrm{C}-\mathrm{Cl}$ aromatic stretching at $670.15 \mathrm{~cm}^{-1}$, Thiazide $\mathrm{SO}_{2}$ at $1354.60 \mathrm{~cm}^{-1}, \mathrm{C}-\mathrm{H}$ aromatic stretching at $3068.73 \mathrm{~cm}^{-1}$, and $\mathrm{O}-\mathrm{H}$ stretching at $3393.35 \mathrm{~cm}^{-1}$ were there in drug sample spectrum, which confirmed the purity of lornoxicam.

Compatibility study using FTIR was carried out to ensure any possible interaction between drug and Eudragit RS100 and Eudragit RSPO used. FTIR spectroscopic study results revealed no any new peak appearance or disappearance of existing peaks, discarding any chemical interaction probability among drug and polymers used. The characteristic $\mathrm{C}=01^{\circ}$ amide stretching vibration at $1640.91 \mathrm{~cm}^{-1}, \mathrm{~N}-\mathrm{H} 2^{\circ}$ amide stretching at $3123.29, \mathrm{C}-\mathrm{Cl}$ aromatic stretching at $670.05 \mathrm{~cm}^{-1}$, Thiazide $\mathrm{SO}_{2}$ at $1354.71 \mathrm{~cm}^{-1}, \mathrm{C}-\mathrm{H}$ aromatic stretching at $3068.71 \mathrm{~cm}^{-1}$, and $\mathrm{O}-\mathrm{H}$ stretching at $3393.53 \mathrm{~cm}^{-1}$ peaks of lornoxicam were present in the physical mixture of drug and polymers. Thus, FTIR spectroscopy results showed that lornoxicam was compatible with selected polymers (Fig. 2).

\section{SEM}

Morphology of prepared microsponges was discovered by SEM analysis. SEM image of optimized formulation (F12) of lornoxicam microsponges shown in Fig. 3. SEM results indicated that microsponges formed were highly porous, spherical in shape with rough surface texture and tiny particles are adhered on the porous outer surface. Pores were induced by diffusion of solvent from the surface of microsponges.

Percentage yield, percentage of unentrapped drug, percentage entrapment efficiency, and particle size studies of lornoxicam microsponges

The percentage yield of all formulations was carried out and was found within the range between $69.58 \%$ and $75.35 \%$. Percentage of the unentrapped drug was found to be $24.06 \%-30.35 \%$. Entrapment efficiency was found to be $62.24 \%-70.34 \%$. The mean particle size of the microsponges significantly increased with increase in polymer concentration. The reason may be due to the viscosity of medium which increases as the polymer concentration increases. This may be resulting in the formation of larger particles. The particle size of prepared microsponges was observed in the range of 172.72-234.44 $\mu \mathrm{m}$. The sizes of microsponges affect the encapsulation efficiency and the release rate of the drug. It was observed that as the ratio of drug to polymer was increased, the encapsulation efficiency was decreased. This could probably be due to the fact that in high drug to polymer ratio, the amount of polymer available per microsponge was comparatively less. Probably in high drug-polymer ratios less polymer amounts surround the drug and reducing the thickness of polymer wall and microsponges with smaller size were obtained (Table 2).

\section{In vitro drug release}

In vitro, drug release studies were performed in $\mathrm{pH} 6.8$ phosphate buffer for $12 \mathrm{~h}$. The cumulative percentage of drug release of prepared formulations was found to be in the following order: F12> F11 $>$ F6 $>$ $\mathrm{F} 5>\mathrm{F} 10>\mathrm{F} 9>\mathrm{F} 4>\mathrm{F} 3>\mathrm{F} 8>\mathrm{F} 7>\mathrm{F} 2>\mathrm{F} 1$. The percentage drug release of formulations F1, F2, F3, F4, F5, F6, F7, F8, F9, and F10 was found to be $61.21 \%, 65.61 \%, 80.68 \%, 83.25 \%, 92.57 \%, 95.09 \%, 73.46 \%$, $86.65 \%$, and $89.17 \%$, in $12 \mathrm{~h}$ respectively. The percentage drug release of formulation F11 was found to be $95.47 \%$ in $10 \mathrm{~h}$. Formulation F12 showed high release, $95.47 \%$ in $8 \mathrm{~h}$. This could be due to smaller microsponges are formed at a lower polymer concentration and have a large surface area exposed to dissolution medium, giving rise to faster drug release. Hence, it is considered as an optimized formulation.

Results indicate that proportion of polymers in the formulation was the key factor governing the release of drug from microsponges. As the concentration of polymer increased, there was an increase in particle

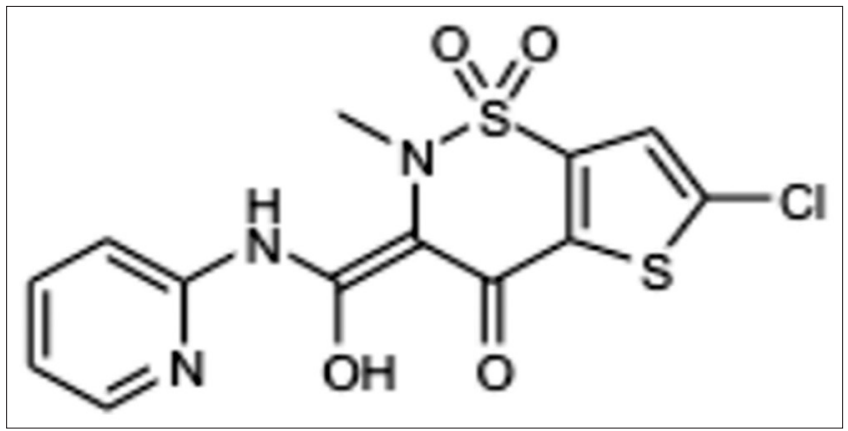

Fig. 1: Lornoxicam

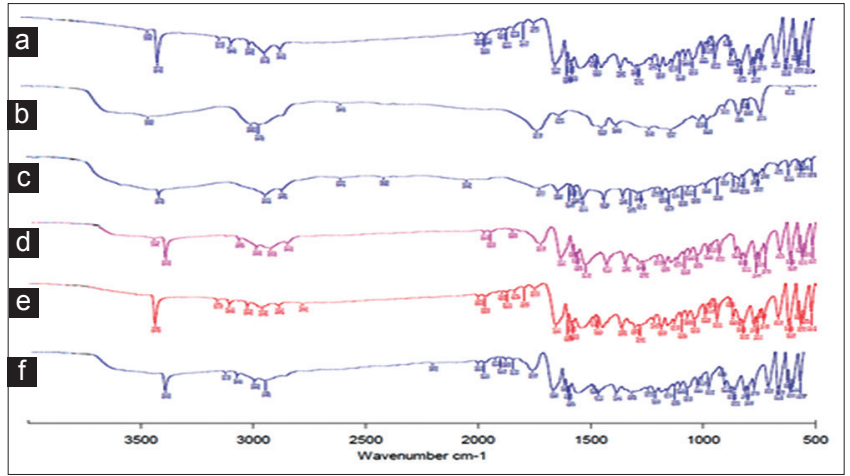

Fig. 2: Fourier-transform infrared Spectras of (a) Lornoxicam (b) Eudragit RSPO, (c) Eudragit RS 100, (d) physical mixture of lornoxicam and Eudragit RSPO, (e) physical mixture of lornoxicam and Eudragit RS 100, (f) physical mixture of lornoxicam, Eudragit RS 100, and Eudragit RSPO

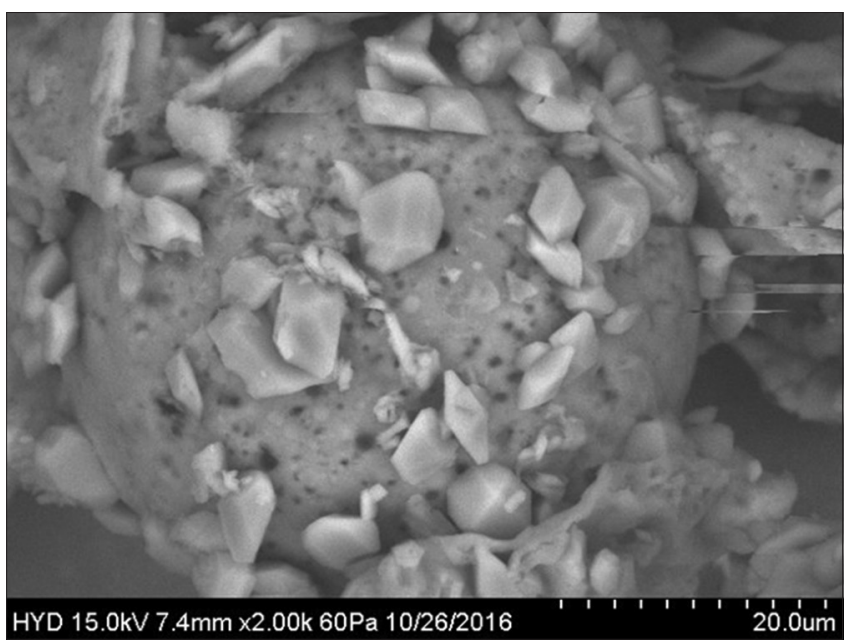

Fig. 3: Scanning electron microscopy photograph of optimised formulation (F12) of lornoxicam microsponges

size and diffusional path length. This may decrease the overall drug release from the polymer matrix. Formulations comprised Eudragit RSPO in higher proportion exhibited much-retarded drug release as compared to formulations comprised Eudragit RS 100 in higher proportion. The drug release profile from microsponges for all the formulations is shown in Figs. 4-7 and Table 3.

Release of lornoxicam from the microsponges for the optimized formulation F12 was found to follow zero-order kinetics (correlation 
Table 2: Percentage yield, Percentage of unentrapped drug, percentage entrapment efficiency, and particle size of lornoxicam microsponges

\begin{tabular}{llll}
\hline Formulation & $\begin{array}{l}\text { Percentage yield } \\
(\% \mathbf{w} / \mathbf{w})^{*}\end{array}$ & $\begin{array}{l}\text { Percentage of } \\
\text { unentrapped drug }(\% \mathbf{w} / \mathbf{w})^{*}\end{array}$ & $\begin{array}{l}\text { Percentage of Entrapment } \\
\text { efficiency }(\% \mathbf{w} / \mathbf{w})^{*}\end{array}$ \\
\hline F1 & $75.08 \pm 0.965$ & $30.35 \pm 1.036$ & $62.24 \pm 1.729$ \\
F2 & $72.21 \pm 1.034$ & $30.27 \pm 1.873$ & $63.50 \pm 1.137$ \\
F3 & $69.58 \pm 0.928$ & $29.23 \pm 2.589$ & $64.41 \pm 2.645$ \\
F4 & $70.16 \pm 2.147$ & $29.54 \pm 2.764$ & $65.29 \pm 2.749$ \\
F5 & $71.43 \pm 2.138$ & $28.48 \pm 1.773$ & $69.65 \pm 1.211$ \\
F6 & $73.12 \pm 1.917$ & $28.82 \pm 1.248$ & $67.75 \pm 1.765$ \\
F7 & $75.35 \pm 1.346$ & $28.57 \pm 2.432$ & $67.75 \pm 1.629$ \\
F8 & $73.92 \pm 3.270$ & $27.34 \pm 2.032$ & $68.27 \pm 1.375$ \\
F9 & $71.28 \pm 2.164$ & $27.83 \pm 1.258$ & $68.57 \pm 2.125$ \\
F10 & $73.65 \pm 1.560$ & $26.67 \pm 1.045$ & $69.21 \pm 1.432$ \\
F11 & $70.45 \pm 1.317$ & $26.19 \pm 2.845$ & $69.68 \pm 2.327$ \\
F12 & $70.23 \pm 1.305$ & $24.06 \pm 2.035$ & $70.34 \pm 1.325$ \\
\hline
\end{tabular}

$*(\mathrm{n}=3)$, (average $\pm \mathrm{SD})$

Table 3: Correlation coefficient $\left(r^{2}\right)$ values of different formulations of lornoxicam microsponges (F1-F12)

\begin{tabular}{|c|c|c|c|c|c|}
\hline \multirow{3}{*}{$\begin{array}{l}\text { Formulation } \\
\text { Code }\end{array}$} & \multicolumn{5}{|l|}{$\mathbf{r}^{2}$ values } \\
\hline & \multirow[t]{2}{*}{ Zero-order $\left(r^{2}\right)$} & \multirow[t]{2}{*}{ First-order $\left(r^{2}\right)$} & \multirow[t]{2}{*}{ Higuchi Model $\left(r^{2}\right)$} & \multicolumn{2}{|c|}{ Korsmayer-Peppas } \\
\hline & & & & $\mathbf{r}^{2}$ value & n Value \\
\hline F1 & 0.981 & 0.928 & 0.881 & 0.954 & 1.408 \\
\hline $\mathrm{F} 2$ & 0.991 & 0.948 & 0.912 & 0.927 & 1.410 \\
\hline F3 & 0.995 & 0.966 & 0.970 & 0.895 & 1.487 \\
\hline F4 & 0.991 & 0.968 & 0.949 & 0.880 & 1.489 \\
\hline F6 & 0.961 & 0.961 & 0.983 & 0.840 & 1.487 \\
\hline F7 & 0.994 & 0.963 & 0.935 & 0.817 & 1.415 \\
\hline F8 & 0.994 & 0.971 & 0.937 & 0.905 & 1.442 \\
\hline F9 & 0.986 & 0.970 & 0.958 & 0.893 & 1.509 \\
\hline F10 & 0.976 & 0.975 & 0.970 & 0.858 & 1.511 \\
\hline F11 & 0.973 & 0.906 & 0.980 & 0.809 & 1.558 \\
\hline F12 & 0.961 & 0.807 & 0.971 & 0.792 & 1.731 \\
\hline
\end{tabular}

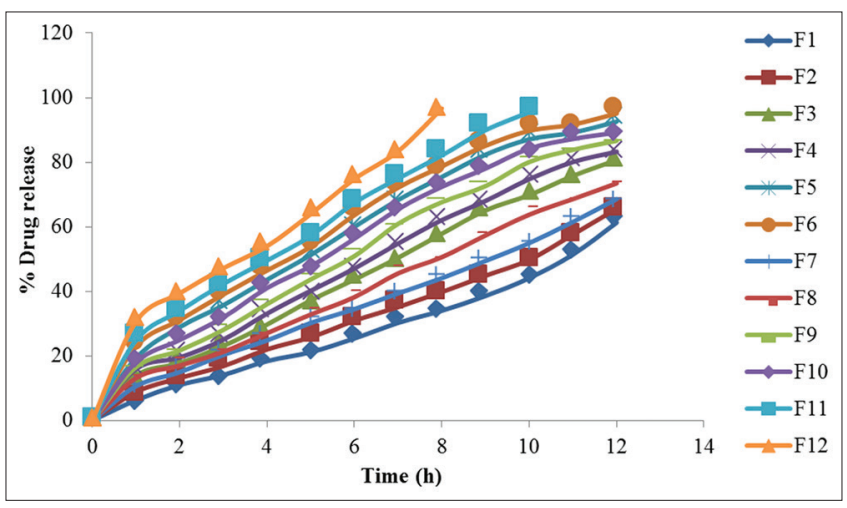

Fig. 4: Zero-order release profile of lornoxicam microsponges (F1-F12) $(n=6)$

coefficient, $r^{2}$ value 0.961$)$. Higuchi plot showed an $r^{2}$ value of 0.971 for optimized formulation F12 suggesting that the diffusion plays an important role in the controlled release. The data were fitted to Korsmeyer-Peppas equation; the value of diffusion exponent " $n$ " for optimized formulation F12 is 1.731, indicated that the drug release follows super case II diffusion.

\section{CONCLUSION}

Microsponges of lornoxicam were prepared by the quasi-emulsion solvent diffusion method using polymers such as Eudragit RS 100 and Eudragit RSPO. As the polymer concentration is increasing, the particle size of microsponges was increased, and the drug release was decreased.

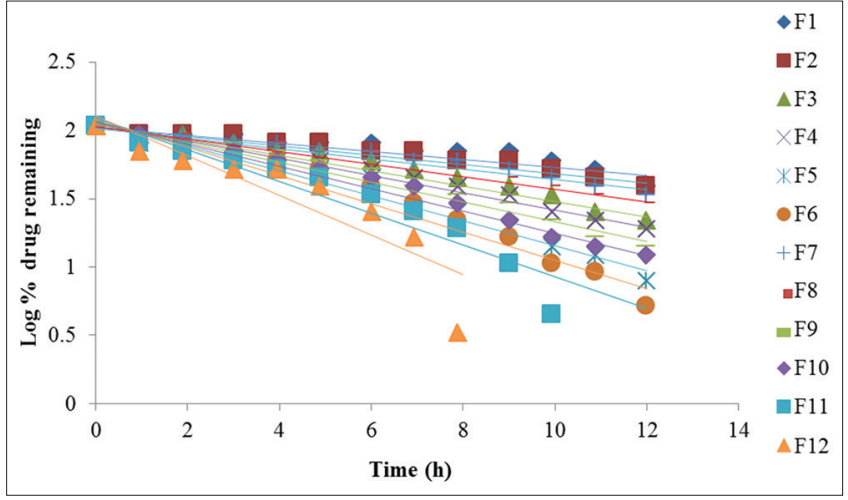

Fig. 5: First-order drug release profile of lornoxicam microsponges (F1-F12) $(n=6)$

Among all the formulations, $\mathrm{F} 12$ shows better results, which are released more than $80 \%$ of the drug release within $8 \mathrm{~h}$. Hence, lornoxicam loaded microsponges prepared by this quasi-emulsion solvent diffusion method are potential for prolong the release of the drug, which will be effective for osteoarthritis, rheumatoid arthritis, and acute lumbar sciatica therapy.

\section{ACKNOWLEDGMENT}

The authors are thankful to management, Nirmala College of Pharmacy, Managalagiri, Guntur (Dist.), A.P., for providing necessary facilities to carry out the research work. 


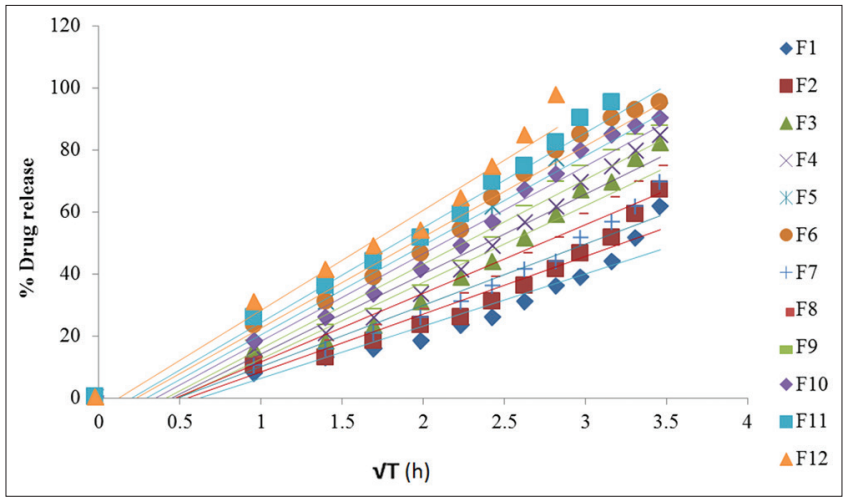

Fig. 6: Higuchi plot of lornoxicam microsponges (F1-F12) $(n=6)$

\section{AUTHOR'S CONTRIBUTIONS}

The first author carried out the experimental part of the work. The second author guided and monitored the experimental design, data compilation, critical revision of the article, and corrected the manuscript and third author data analysis, interpretation, and drafting the article.

\section{CONFLICTS OF INTEREST}

All the authors hereby declare that there are no conflicts of interest.

\section{REFERENCES}

1. Jain N, Sharma PK, Banik A. Recent advances on microsponge delivery system. Int J Pharm Pharm Sci 2011;2:13-23.

2. Kaity S, Maiti S, Ghosh AK, Pal D, Ghosh A, Banerjee S, et al. Microsponges: A novel strategy for drug delivery system. J Adv Pharm Technol Res 2010;1:283-90.

3. Kumar R, Sharma SK, Jaimini M, Alam N. Microsponge drug delivery systems for novel topical drug delivery. Int J Pharm Sci Lett 2014;3:384-90.

4. Ravi R, Kumar SK, Parthiban S. Formulation and evaluation of the microsponges gel for an anti acne agent for the treatment of acne. Indian J Pharma Sci 2013;1:32-8.

5. Osmani RA, Aloorkar NH, Thaware BU, Kulkarni PK, Moin A, Hani $\mathrm{U}$, et al. Microsponge based drug delivery system for augmented gastroparesis therapy. Asian J Pharm Sci 2015;5:442-51.

6. Osmani RA, Aloorkar NH, Ingale DJ, Kulkarni PK, Hani U,

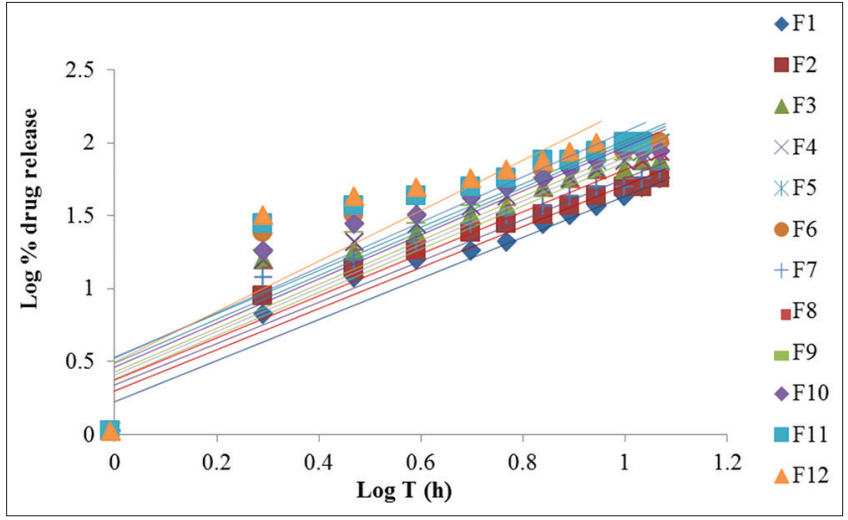

Fig. 7: Korsmeyer-Peppas plots of lornoxicam microsponges (F1-F12) $(n=6)$

Bhosale RR, et al. Microsponges based novel drug delivery system for augmented arthritis therapy. Saudi Pharm J 2015;5:562-72.

7. Available from: https://www.en.wikipedia.org/wiki/Lornoxicam. 8. Availablefrom:https://www.medindia.net/doctors/drug_informatio $\mathrm{n} /$ lornoxicam.htm.

9. Available from: http://www.auburn.edu/ deruija/nsaids_2002.pdf.

10. Rekha U, Manjula BP. Formulation and evaluation of microsponges for topical drug delivery of mometasone furoate. Int J Pharm Pharm Sci 2011;4:133-7.

11. Harsh S, Patel K, Upadhyay UM. Formulation and evaluation of controlled release colon targeted micro sponge of aceclofenac. Pharma Innov J 2014;10:81-7.

12. Rajab NA, Jawad MS. Formulation and in vitro evaluation of piroxicam microsponge as a tablet. Int J Pharm Pharm Sci 2015;2:104-14.

13. Zia R, Nazir A, Khan MK, Maan AA, Rashid A. Preparation of ascorbic acid and cholecalciferol microsponges for topical application. Int $\mathrm{J}$ Pharm Pharm Sci 2017;10:280-7.

14. Thireesha B, Prasad AR. Development and validation of a simple UV spectrophotometric method for the determination of lornoxicam in 0.75\% w/v PVA solution. Indo Am J Pharm Res 2016;9:6470-7.

15. Prasad AR, Thireesha B. UV-Spectrophotometric method development and validation for the determination of lornoxicam in microsponges. Int J App Pharm 2018;1:74-8.

16. Prasad AR, Thireesha B. Development and validation of a simple UV spectrophotometric method for the determination of lornoxicam in pH 7.4 phosphate buffer. Indo Am J Pharm Res 2016;9:6478-85. 